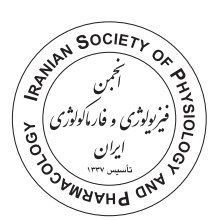

\title{
Anticonvulsant effect of acute curcumin nanoparticle on pentylenetetrazole-induced seizures in mice: non-involvement of $\mathrm{JNK}$ restoration
}

\section{Leila Moezi ${ }^{1,2 \#}$, Nahid Ashjazadeh ${ }^{3 \#}$, Shirin Rezapanah ${ }^{3}$, Fatema Pirsalami², Zahra Esmaeili ${ }^{1,4}$, Roksana SoukhakLari ${ }^{4,5}$,} Maryam Moosavi ${ }^{1 *}$ (D)

1. Nanobiology and Nanomedicine Research Centre, Shiraz University of Medical sciences, Shiraz, Iran

2. Department of Pharmacology, Medical School, Shiraz University of Medical sciences, Shiraz, Iran

3. Clinical Neurology Research Center and Department of Neurology, Shiraz University of Medical Sciences, Shiraz, Iran

4. Shiraz Neuroscience Research Centre, Shiraz University of Medical sciences, Shiraz, Iran

5. Students Research Committee, School of Medicine, Shiraz University of Medical Sciences, Shiraz, Iran

\begin{abstract}
Introduction: Although several animal studies have indicated the antiepileptic effect for curcumin, there are reports stating the null antiepileptic effect of this substance. This inconsistency might be due to the low bioavailability of curcumin. Therefore, the current study aimed to assess the effect of oral bovine serum albumin (BSA)-based nanocurcumin on seizure caused by pentylenetetrazol (PTZ) in mice. Furthermore, due to the suggested involvement of JNK signaling in seizure pathology, the hippocampal pattern of JNK phosphorylation (activation) was evaluated. Methods: BSA based nanocurcumin was administered at doses of 50 and $100 \mathrm{mg} / \mathrm{kg}$ oral gavage to male NMRI mice, one hour before PTZ administration. Intravenous PTZ paradigm was used to determine the threshold dose of PTZ to induce clonic seizures, while the intraperitoneal PTZ paradigm was applied to evaluate the latency for appearance of generalized clonus. Upon completion of intraperitoneal PTZ paradigm experiments, the hippocampi were removed and Western blot analysis was performed to determine the phosphorylated and total forms of JNK.

Results: The results indicated that BSA-based nanocurcumin at the doses of 50 and $100 \mathrm{mg} / \mathrm{kg}$ could significantly increase the threshold and latency of clonic seizure, which was a significant superior effect compared to natural curcumin. PTZ significantly increased the level of hippocampal JNK phosphorylation, but pretreatment of nanocurcumin did not modify this effect.

Conclusion: The present study shows that converting curcumin to BSA-based nanocurcumin can increase its antiepileptic effect. Furthermore, the antiepileptic effect of nanocurcumin was not associated with a modification in PTZ-induced hippocampal JNK hyper activation.
\end{abstract}

\section{Introduction}

Epilepsy, as one of the most prevalent and treatable neurologic diseases, is characterized by the abnormal activity of brain neural cells (Duncan et al., 2006). The available anti-epileptic medications can control epilepsy in about two thirds of the patients, but the remaining

\footnotetext{
* Corresponding author: Maryam Moosavi, marmoosavi@sums.ac.ir

\# These authors contributed equally to this work and are considered as co-first authors.

Received 8 July 2020; Revised from 20 September 2020; Accepted 27 October 2020

Citation: Moezi L, Ashjazadeh N, Rezapanah S, Pirsalami F, Esmaeili Z, SoukhakLari R, Moosavi M. Anticonvulsant effect of acute curcumin nanoparticle on pentylenetetrazole-induced seizures in mice: non-involvement of JNK restoration. Physiology and Pharmacology 2021; 25: 36-46. http://dx.doi.org/10.32598/ ppj.25.1.80
} 
suffer from the symptoms and regarded to be in the state of refractoriness (Tang et al., 2017). Additionally, the current anti-epileptic drugs have adverse effects, some of these anti-epileptic medications might even lead to hepatotoxicity (Vidaurre et al., 2017).

Herbal extracts are regarded as potential remedies in treating epilepsy. Curcumin is a polyphenolic phytochemical compound, extracted from Curcumalonga (turmeric) (Kocaadam and Sanlier, 2017). Curcumin is reported to have therapeutic effect on epilepsy. For example, it was shown to possess protective effect in iron-induced epilepsy model (Kumar et al., 2019), acute intraperitoneal pentylenetetrazol (PTZ) induced seizure (Akula and Kulkarni, 2014; Jahan et al., 2018), chronic intraperitoneal PTZ induced kindling model (Choudhary et al., 2013; Saha et al., 2016), kainate-induced epilepsy (Kiasalari et al., 2013) and pilocarpine-induced seizures (Peng et al., 2012). However, there are other studies reporting the null antiepileptic effect of curcumin in PTZ-induced seizures (Kaur et al., 2014), the seizures induced by kainic acid (Sumanont et al., 2007) and the seizure frequency in post-status epilepticus model of temporal lobe epilepsy (Drion et al., 2016). The absence of curcumin's anti-epileptic effect in several studies might be due to its restricted accessibility to the brain since curcumin has low solubility in water (Tønnesen, 2002). Many animal and clinical studies in rodents and humans showed the low bioavailability of curcumin (Aggarwal et al., 2007; Goel et al., 2008). Subsequently, curcumin's potential as a therapy might be restricted by its poor aqueous solubility and low oral bioavailability (Flora et al., 2013). Different strategies have been followed to improve curcumin absorption including the formulation of curcumin nanoparticles to enhance its water solubility and capability to cross the blood-brain barrier (Hashemian et al., 2017). In line, curcumin nanoparticles loaded on chitosan-alginatesodium tripolyphosphate showed to reduce memory deficit and cell loss in PTZ kindling model of epilepsy (Hashemian et al., 2017). Additionally, it was shown that the liposomal formulations of curcumin attenuate seizures in different animal models of epilepsy, including PTZ-induced seizures, current electroshock seizures and status epilepticus in mice (Agarwal et al., 2013). Among the widespread biomolecules used for delivery of nanoparticles, albumin protein has some priority due to its nontoxicity and non-immunogenicity
(Kratz, 2008). This protein is considered as a safe carrier for curcumin due to these properties and increases the bioavailability in comparison to native curcumin (Jithan et al., 2011; Delfiya et al., 2016). It was previously shown that albumin-based nanocurcumin has higher based nanocurcumin bioavailability in comparison to native curcumin both in vivo (SoukhakLari et al., 2018c; SoukhakLari and Moezi, 2019) and in vitro (Sookhaklari et al., 2019).

Several studies indicate that epileptic seizures cause damage to hippocampal neurons, which in turn might be one of the most important factors in the reconstruction of loop during recurrent seizures (Buckmaster et al., 2014). The c-Jun N-terminal kinase (JNK) belongs to the mitogen activated protein kinases family and takes part in a wide range of biologic processes, such as inflammation and apoptosis (Yarza et al., 2016). Hence, it was proposed that JNK hyper activation might play a role in the pathogenesis of intractable epilepsy (Tai et al., 2017). The contribution of JNK has been shown in different chronic models of epilepsy, such as kainic acid (Mielke et al., 1999; Hsieh et al., 2007), electrical kindling models (Cole-Edwards et al., 2006), PTZ kindling model (Ben et al., 2014), as well as in acute model of PTZ-induced seizures (Morgan et al., 2006). The suppression of JNK pathway was previously reported to be involved in the therapeutic effects of curcumin (Collett and Campbell, 2004; Geng et al., 2018; Zhao et al., 2018). In the hippocampus, dietary curcumin administration reduced lipopolysaccharide induced hippocampal phosphorylated JNK elevation (Khan and Muhammad, 2019). Furthermore, the memory enhancing effect of nanocurcumin coincided with a diminished hippocampal JNK phosphorylation (SoukhakLari et al., 2018c).

In the current study, the effect of acute oral bovine serum albumin (BSA)-based nanocurcumin administration on the threshold and latency of clonic seizures induced by intravenous or intraperitoneal injection of PTZ in mice was assessed, and the results were compared with native form of curcumin. Moreover, considering the reported over activation of JNK in seizure, it was assessed to see if the potential antiepileptic effect of BSA based nanocurcumin coincides with JNK modulation.

\section{Materials and Methods}

Materials 
PTZ was purchased from Sigma-Aldrich Corporation (St. Louis, MO, USA). Curcumin was bought from Exir GmbH, Austria. For western blot analysis, phosphorylated-JNK (p-JNK), total JNK (t-JNK), betaactin and secondary HRP-conjugated antibodies were provided by Cell Signaling Technology (Danvers, MA, USA). Amersham ECL select reagent kit was supplied from GE Healthcare Life Sciences, UK. Protease and phosphatase inhibitor was from Pierce, and PVDF membrane was purchased from Millipore. Other reagents were provided from the usual commercial sources.

\section{BSA-based nanocurcumin preperation}

In accordance with earlier studies (Delfiya et al., 2016; SoukhakLari et al., 2018c; Sookhaklari et al., 2019; SoukhakLari and Moezi, 2019), BSA was used as the polymer to prepare nanocurcumin. Briefly, $2.5 \%$ curcumin solution (in aceton) was added alternatingly to $3 \%$ BSA solution (in distilled water) on a magnetic stirrer. Afterward, $110 \mu 1$ of $8 \%$ glutaraldehyde solution (in distilled water) was added to the turbid solution to achieve a cross-linkage of the nanoparticles; a process performing on the magnetic stirrer overnight at $4^{\circ} \mathrm{C}$. Differential centrifugation (3000 rpm, 30min) was used to purify the resultant suspension (over 5 cycles). Lastly, the resulted pellet was dried by means of a freeze drier to achieve a powder. According to the previous publications, this desolvation technique led to the production of quite regular round nanoparticles with mean diameters of about 140nm (SoukhakLari et al., 2018c; Sookhaklari et al., 2019; SoukhakLari and Moezi, 2019).

\section{Animals}

Male NMRI mice (age 8-10 weeks, weight 25-30g) were obtained from the animal lab of Shiraz University of Medical Sciences. The animals had access to water and food ad libitum and were kept under controlled lighting (07:00 to $19: 00)$ and temperature $\left(20 \pm 2^{\circ} \mathrm{C}\right)$ status. All experimental protocols were approved by the Shiraz University of Medical Sciences Animal Care and Use Committee in accordance with the National Institutes of Health Guidelines (approval number: IR.SUMS.REC.1398.674). Each mouse was used once and each group consisted of 6-8 mice.

\section{Behavioral seizure evaluation}

Experiment 1: Assessment of the effect of nanocurcumin on seizure threshold

An intravenous (i.v.) PTZ infusion with a continuous flow rate provokes seizure in a reproducible, reliable and rapid manner (Mandhane et al., 2007). This test determines the threshold dose of PTZ to prompt seizures contrary to fixed dose PTZ paradigms that detect latency time to induce seizures (Mandhane et al., 2007). The screening of potential anti-epileptic effect of a substance through the intravenous PTZ test, usually provides better insight about its modulatory effects on seizure susceptibility (Loscher et al., 1991). A dental needle (30-gauge) was placed in the lateral tail vein of the animal. The precision of needle location in the vein was confirmed by arrival of blood in the cannula. An adhesive tape was used to secure the needle to the tail. While the animal was moving freely, the $0.5 \%$ PTZ solution (diluted in saline) was infused, using an infusion pump (Harvard, USA) at a continual rate of $0.5 \mathrm{ml} / \mathrm{min}$. The time latency till the appearance of first clonus subsequent to full clonus of the body was recorded (Shafaroodi et al., 2015; Moezi et al., 2018; Inaloo et al., 2019). The threshold dose of PTZ for the appearance of clonic seizure was calculated using the following formula:

$P T Z\left(\frac{m g}{k g}\right)=\frac{\text { infusion duration }(s) \times \text { infusion rate }\left(\frac{m l}{s}\right) \times P T Z \text { concentration }\left(\frac{m g}{m l}\right)}{\text { weight }(\mathrm{kg})}$

To determine the potential effective doses of nanocurcumin, a preliminary study was performed during which nanocurcumin at the doses of 25, 50 and $100 \mathrm{mg} / \mathrm{kg}$ oral gavage (SoukhakLari et al., 2018b; SoukhakLari et al., 2018a) was dissolved in distilled water and then administered 60min before PTZ infusion (data not shown). Accordingly, the doses 50 and $100 \mathrm{mg}$ were chosen as effective doses for further investigations. Moreover, two other separate groups received natural curcumin at the equal doses of 50 and $100 \mathrm{mg} / \mathrm{kg}$. Mice were divided into 5 groups ( $\mathrm{n}=6-8 /$ each group) as below:

1- i.v.PTZ group $(\mathrm{n}=8)$ : administered distilled water/ oral gavage (vehicle for nanocurcumin) $1 \mathrm{~h}$ before the venous infusion of threshold dose of PTZ (dissolved in saline); 2- i.v.PTZ+ nanocurcumin $50 \mathrm{mg} / \mathrm{kg}(\mathrm{n}=8)$ : received nanocurcumin $50 \mathrm{mg} / \mathrm{kg}$ oral gavage $1 \mathrm{~h}$ before the venous infusion of threshold dose of PTZ; 
3- i.v.PTZ+ nanocurcumin $100 \mathrm{mg} / \mathrm{kg}(\mathrm{n}=7)$ : received nanocurcumin $100 \mathrm{mg} / \mathrm{kg}$ oral gavage $1 \mathrm{~h}$ before the venous infusion of threshold dose of PTZ; 4- i.v.PTZ+ curcumin $50 \mathrm{mg} / \mathrm{kg}(\mathrm{n}=6)$ : received curcumin $50 \mathrm{mg} / \mathrm{kg}$ oral gavage $1 \mathrm{~h}$ before the venous infusion of threshold dose of PTZ; 5- i.v.PTZ+ curcumin $100 \mathrm{mg} / \mathrm{kg}(\mathrm{n}=8)$ : administered curcumin $100 \mathrm{mg} / \mathrm{kg}$ oral gavage $1 \mathrm{~h}$ before the venous infusion of threshold dose of PTZ.

\section{Experiment 2: Assessment of the effect of nanocurcumin} on seizure latency

In this experiment, intraperitoneal PTZ (85mg/ $\mathrm{kg}$, dissolved in saline) was injected $60 \mathrm{~min}$ following nanocurcumin, curcumin or vehicle administration. This dose induces a generalized tonic-clonic seizure, which resembles tonic-clonic seizures in human (Loscher et al., 1991; Kupferberg, 2001). Immediately following i.p.PTZ administration, animals were observed for the appearance of generalized clonus and the latency to this phase was measured (Loscher and Lehmann, 1996; Shafaroo di et al., 2012). Latency was assumed as the time interval between i.p.PTZ injections and the initiation of seizure. The animals were divided into 5 groups $(n=7-8 /$ each group) as below:

1 - i.p.PTZ group $(n=7)$ : received distilled water, oral gavage (vehicle for nanocurcumin) $1 \mathrm{~h}$ before the intraperitoneal PTZ at the dose of $85 \mathrm{mg} / \mathrm{kg}$ (dissolved in saline); 2- i.p.PTZ+ nanocurcumin $50 \mathrm{mg} / \mathrm{kg}(\mathrm{n}=7)$ : received nanocurcumin $50 \mathrm{mg} / \mathrm{kg}$ oral gavage $1 \mathrm{~h}$ before the intraperitoneal PTZ at the dose of $85 \mathrm{mg} / \mathrm{kg}$; 3i.p.PTZ+ nanocurcumin $100 \mathrm{mg} / \mathrm{kg} \quad(\mathrm{n}=8)$ : received nanocurcumin $100 \mathrm{mg} / \mathrm{kg}$ oral gavage $1 \mathrm{~h}$ before the intraperitoneal PTZ at the dose of $85 \mathrm{mg} / \mathrm{kg}$; 4- i.p.PTZ+ curcumin $50 \mathrm{mg} / \mathrm{kg}(\mathrm{n}=7)$ : received curcumin $50 \mathrm{mg} / \mathrm{kg}$ oral gavage $1 \mathrm{~h}$ before the intraperitoneal $\mathrm{PTZ}$ at the dose of $85 \mathrm{mg} / \mathrm{kg}$; 5- i.p.PTZ+ curcumin $100 \mathrm{mg} / \mathrm{kg}(\mathrm{n}=7)$ : received curcumin $100 \mathrm{mg} / \mathrm{kg}$ oral gavage $1 \mathrm{~h}$ before the intraperitoneal PTZ at the dose of $85 \mathrm{mg} / \mathrm{kg}$.

\section{Tissue preparation}

The hippocampal tissues of animals included in experiment 2, were isolated for Western blot studies. Immediately following i.p.PTZ experiment, the brains of the control, PTZ and PTZ+ nanocurcumin groups $(n=4-6$ mice/each group, randomly selected) were isolated, after light $\mathrm{CO} 2$ anesthesia and the guillotine method of decapitation. The hippocampi were isolated on ice, directly frozen in liquid nitrogen and kept in $-80^{\circ} \mathrm{C}$. Cold RIPA lysis buffer inclosing protease and phosphatase inhibitors was used to homogenize hippocampal tissues. Centrifugation at 14000rpm for $20 \mathrm{~min}\left(4^{\circ} \mathrm{C}\right)$ was performed on the lysates to remove the supernatant. Lowry method (Lowry et al., 1951) was used to determine the protein content of supernatant.

\section{Western blot analysis}

The Western blot technique was performed as formerly described (Moosavi, Abbasi et al. 2014, Amiri, Ghasemi et al. 2016). Equal amount of protein sample $(40 \mu \mathrm{g})$ was loaded on a $10 \%$ SDS-PAGE and then transferred onto PVDF membranes (Millipore, Burlington, MA, United States), using Bio-Rad transfer system (Bio-Rad, USA). The $5 \%$ BSA in TBST $(100 \mathrm{mM}$ Tris, $2.0 \% \mathrm{NaCl} \mathrm{pH}$ $7.6,1 \%$ Tween-20) was used as the blocking agent. The primary antibodies, p-JNK (1:2000), t-JNK (1/3000) and beta-actin $(1 / 2000)$ were exposed to PVDF membranes overnight at $4{ }^{\circ} \mathrm{C}$. After washing with TBST, the blots were incubated in horseradish-peroxidase-conjugated secondary anti-rabbit antibody (1/5000) for $1 \mathrm{~h}$. The blot was then washed three times with TBST. Enhanced chemiluminescence (ECL select; GE Healthcare) was used to illuminate the bands. The blots were then exposed to photographic film in a dark room. ImageJ software from NIH (Bethesda, MD, USA) was used to quantify the intensities of protein bands.

\section{Statistical analysis}

Prism 6 (GraphPad Software, San Diego, CA) was used for one-way ANOVA (analysis of variance) followed by Tukey's post hoc test. Differences between groups were considered significant at $P<0.05$. The data are expressed as mean \pm SEM.

\section{Results}

Experiment 1: Nanocurcumin increased the threshold dose of i.v.PTZ induced seizure

Figure 1 shows the effect of nanocurcumin or natural curcumin at the doses of 50 and $100 \mathrm{mg} / \mathrm{kg}$ on i.v.PTZinduced clonic seizure threshold. One-way ANOVA revealed a significant difference between groups $(\mathrm{F}(4,32)=48.42, P<0.0001)$. Post hoc Tukey's test indicated that a single oral gavage of nanocurcumin at the doses of 50 and $100 \mathrm{mg} / \mathrm{kg}, 1 \mathrm{~h}$ before PTZ administration, significantly increased the threshold of 
seizure in comparison with the PTZ group, demonstrating its antiepileptic effect $(P<0.0001)$. As it is depicted in Figure 1, the antiepileptic effect of nanocurcumin appeared at the dose of $50 \mathrm{mg} / \mathrm{kg}$, the dose at which natural curcumin had no significant antiepileptic effect. The antiepileptic effect of natural curcumin appeared at the dose of $100 \mathrm{mg} / \mathrm{kg}$ upon which nanocurcumin exerted a significant superior effect $(P<0.0001)$ compared to natural curcumin.

Experiment 2: Nanocurcumin increased the latency of generalized clonus in i.p.PTZ induced seizure paradigm

The effect of nanocurcumin on i.p.PTZ induced generalized tonic-clonic seizure was assessed in i.p.PTZ induced seizure paradigm. Figure 2 shows the effect of acute administration of nanocurcumin or curcumin at the doses of 50 and $100 \mathrm{mg} / \mathrm{kg}$ on the onset of clonic seizure induced by i.p.PTZ. One-way ANOVA revealed a significant difference between groups $(\mathrm{F}(4,31)=49.08$, $P<0.0001)$. Acute gavage of nanocurcumin significantly increased the clonic seizure latency at both doses of 50 $(P<0.01)$ and $100 \mathrm{mg} / \mathrm{kg}(P<0.0001)$. Natural curcumin increased clonic seizure latency at the dose of $100 \mathrm{mg} / \mathrm{kg}$ $(P<0.0001)$, but not at $50 \mathrm{mg} / \mathrm{kg}$.

Effect of nanocurcumin on the phosphorylation levels of hippocampal JNK in i.p.PTZ induced seizure paradigm

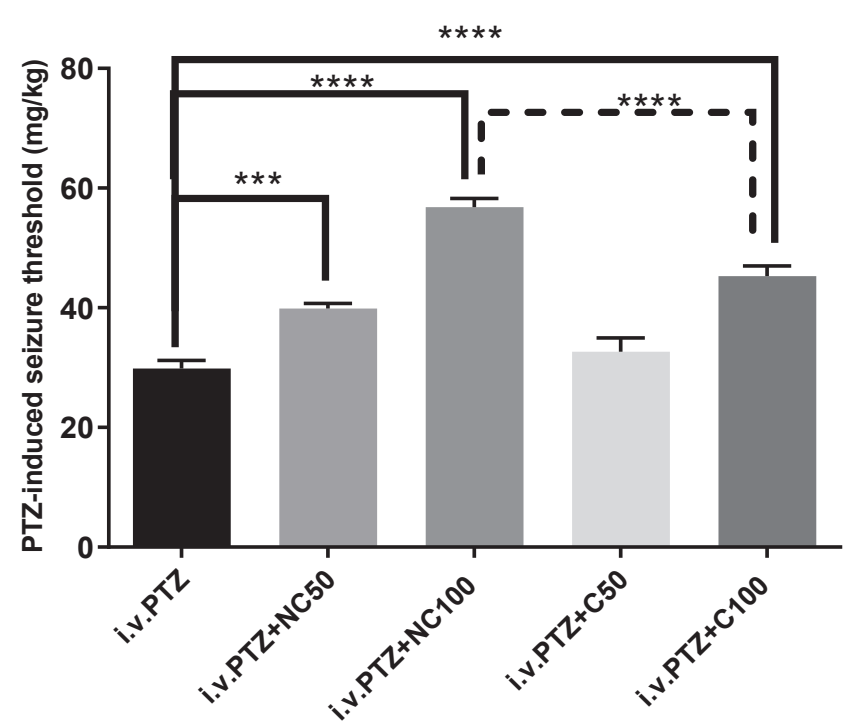

FIGURE 1. The effect of nanocurcumin or curcumin at the doses of 50 and $100 \mathrm{mg} / \mathrm{kg}$ on the threshold dose of PTZ in i.v.PTZ paradigm. Data are presented as mean \pm SEM. ${ }^{* * *} P<0.001$ and ${ }^{* * * *} P<0.0001$ compared with the i.v.PTZ group. $\mathrm{NC}$ represents nanocurcumin and $\mathrm{C}$ represents curcumin.
Figure 3A shows the demonstrative bands of p-JNK, $\mathrm{JNK}$ and beta actin (as an internal control), determined via Western blot technique in control, i.p.PTZ with/ without nanocurcumin at the doses of 50 and $100 \mathrm{mg} / \mathrm{kg}$. The ratio of p-JNK /JNK is shown in Figure 3B. Oneway ANOVA showed a significant difference between groups $(\mathrm{F}(3,14)=8.47, P=0.0019)$. Post hoc Tukey test indicated that PTZ significantly increased the level of hippocampal p-JNK/JNK $(P<0.05)$. Pretreatment of nanocurcumin did not affect PTZ induced elevation of hippocampal p-JNK/JNK.

\section{Discussion}

Oral administration is considered as the most comfortable way to deliver a drug (Scheepens et al., 2010; Rein et al., 2013). However, due to low solubility of curcumin following its oral administration, more than $75 \%$ of it, excretes in feces (Wahlstrom and Blennow, 1978). It was suggested that BSA based nanocurcumin represents a superior therapeutic effect over natural curcumin (SoukhakLari et al., 2018c; Sookhaklari et al., 2019; SoukhakLari and Moezi, 2019). Considering the non-antigenic and non-toxic properties of BSA (Jithan et al., 2011; Delfiya et al., 2016), the present study aimed to evaluate whether oral gavage of BSA based nanoparticles increases its efficacy in i.v.PTZ and/or i.p.PTZ seizure paradigms.

Animal seizure models are extensively used in

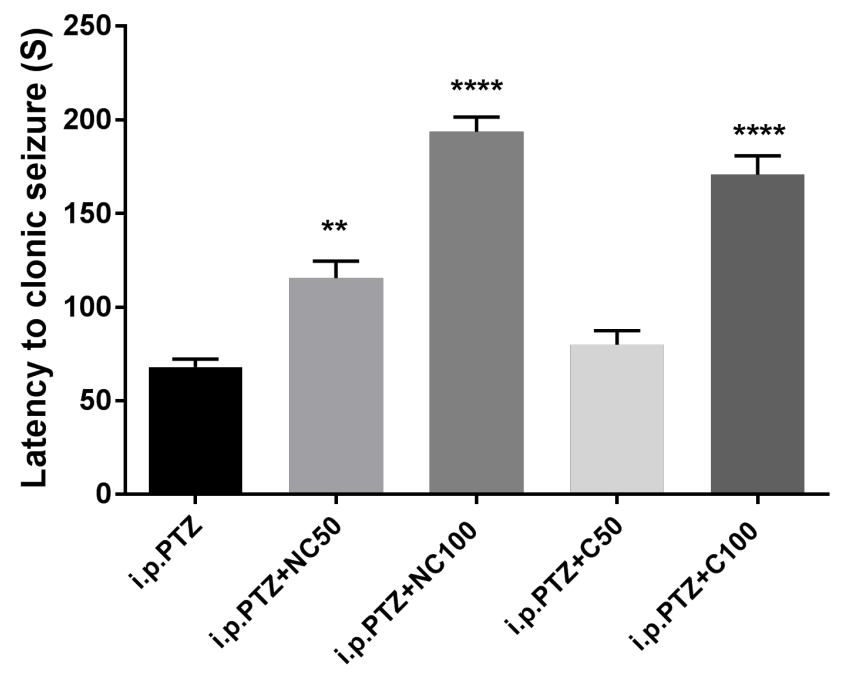

FIGURE 2. The effect of nanocurcumin or curcumin at the doses of 50 and $100 \mathrm{mg} / \mathrm{kg}$ on latency time to clonic seizure induced by intraperitoneal PTZ administration. Data are presented as mean \pm SEM. ${ }^{* *} P<0.01$ and ${ }^{* * * *} P<0.0001$ show the statistical difference between groups. NC represents nanocurcumin and $\mathrm{C}$ represents curcumin. 
A.

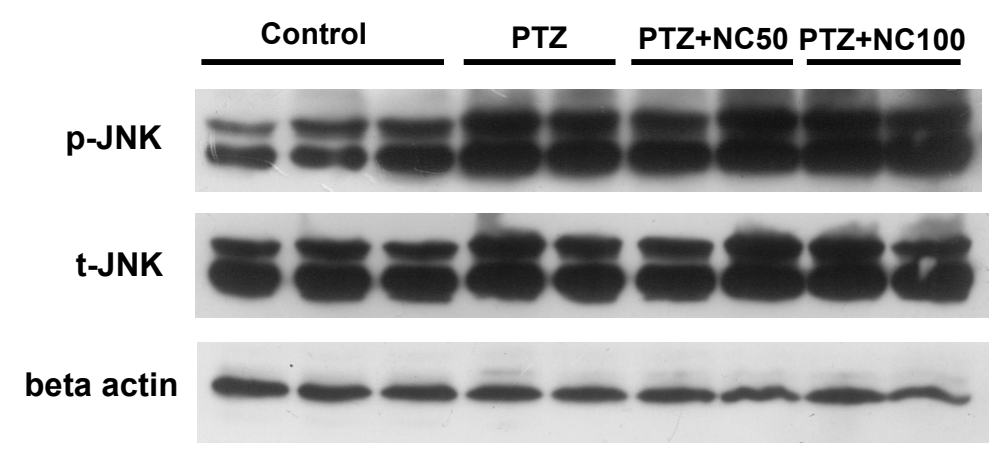

B.

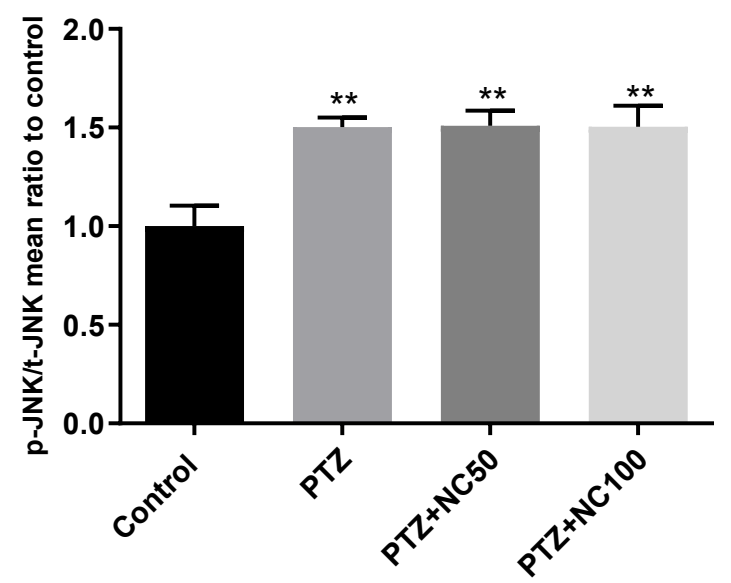

FIGURE 3. The effect of nanocurcumin or curcumin at the doses of 50 and $100 \mathrm{mg} / \mathrm{kg}$ on latency time to clonic seizure induced by intraperitoneal PTZ administration. Data are presented as mean $\pm \mathrm{SEM}$. $* * \mathrm{P}<0.01$ show the statistical difference between groups. NC represents nanocurcumin and $\mathrm{C}$ represents curcumin.

epilepsy research to identify and characterize the new antiepileptic agents (Rogawski, 2006). PTZ blocks GABAA receptor by interacting with its picrotoxin site (Huang et al., 2001). In this study, a single intraperitoneal fixed dose of PTZ was used to measure the latency of seizure response (Mandhane et al., 2007). However, since the calculation of PTZ threshold dose to induce seizure is impossible via the fixed dose method, intravenous PTZ infusion (Nutt et al., 1986) was also utilized to assess PTZ dose threshold and seizure susceptibility (Mandhane et al., 2007).

In the present study, using both i.v.PTZ and i.p.PTZ paradigms, it was shown that a single oral gavage of nanocurcumin increased both the seizure threshold and latency, indicating its potential antiepileptic effect. This protective effect appeared at the dose of $50 \mathrm{mg} / \mathrm{kg}$ while the same dose of natural curcumin did not have any significant effect on seizure. Although, natural curcumin showed an antiepileptic effect at the dose of $100 \mathrm{mg} / \mathrm{kg}$, its equivalent dose of nanocurcumin showed a significant stronger antiepileptic effect on seizure threshold in i.v.PTZ paradigm. This higher efficacy of nanocurcumin can be attributed to its greater bioavalability, since the smaller diameter of curcumin nanoparticles, evidently affects its solubility (Jithan et al., 2011; Kim et al., 2011). Previously, intraperitoneal injection of curcumin C3 complex nanoparticles $(50 \mathrm{mg} / \mathrm{kg} /$ day) for 4 consecutive days was shown to attenuate pilocarpine rat model of status epilepticus (Khadrawy et al., 2018). In PTZinduced kindling model of status epilepticus in mice, intraperitoneal injection of curcumin-loaded chitosanalginate-STPP nanoparticles for 20 days exhibited an anticonvulsant activity (Hashemian et al., 2017). A single liposomal formulation of curcumin was shown to attenuate seizure latency induced by intraperitoneal PTZ (Agarwal et al., 2013).

As it was mentioned before, among the widespread biomolecules used for delivery of nanoparticles, albumin 
protein has some priority due to its nontoxicity and nonimmunogenicity (Kratz, 2008). BSA is broadly used for drug delivery due to its nontoxicity, biocompatibility, biodegradability, abundance and non-immunogenicity. Additionally, BSA improves the water-solubility of prodrugs (Karimi et al., 2016). Based on these properties of BSA and the previous research work on BSA based nanocurcumin (SoukhakLari et al., 2018c; Sookhaklari et al., 2019; SoukhakLari and Moezi, 2019), the present study evaluated the effect of this type of nanocurcumin on both seizure threshold and latency in PTZ model of animal seizure. The threshold dose of PTZ for provoking seizure cannot be calculated, using fixed dose PTZ administration, which detect the time latency to induce seizures (Mandhane et al., 2007). Therefore, i.v.PTZ method was applied to determine seizure threshold, which is an implicational characteristic in screening the potential anti-epileptic effect of a substance on seizure susceptibility (Loscher et al., 1991). Moreover, in the present study, the effect of nanocurcumin was compared with native curcumin, showing a significant superior effect in i.v.PTZ model.

Previous studies have shown that epileptic seizures cause damage to hippocampus and this damage might be one of the most important factors in the reconstruction of loop during recurrent seizures (Buckmaster et al., 2014). JNK becomes activated in response to numerous stress signals and has been shown to be involved in various cellular events, including excitotoxic hippocampal injury following seizures (Spigolon et al., 2010; Zhao et al., 2012). Therefore, the additional aim of this study was to assess the hippocampal JNK activation (phosphorylation). The animals received a fix dose of PTZ in i.p.PTZ model were selected for JNK signaling assay. A control group receiving the vehicles of PTZ and nanocurcumin was included in Western blot study to assess PTZ effect on hippocampal JNK phosphorylation. The results indicated that a single administration of i.p.PTZ at the dose of $85 \mathrm{mg} / \mathrm{kg}$ induced a significant increase in $\mathrm{p}-\mathrm{JNK} / \mathrm{t}-\mathrm{JNK}$ ratio, indicating potent JNK activation. This finding is in line with previous studies, showing an increase in JNK activation following kainic acid or pilocarpine model of epilepsy in the brain or hippocampal area (Mielke et al., 1999; Tai et al., 2017). The pharmacological inhibition of JNK activity or its genetic deletion was shown to protect against neuronal loss induced by kainate or kindling (Yang et al., 1997;
Cole-Edwards et al., 2006; Wang et al., 2015). It was suggested that the inhibition of JNK phosphorylation might serve as a possible target for antiepileptic drugs development. In this line, the antiepileptic effects of agents such as ketogenic diet, acylated ghrelin as well as baclofen and muscimol co-application were shown to be associated with JNK signaling inhibition (Zhang et al., 2018).

Previous works showed that curcumin acts as an inhibitor of JNK. For instance, curcumin inhibited JNK in a rat model of LPS-induced neurotoxicity (Khan and Muhammad, 2019) and treatment of mice with curcumin alone led to a significant reduction in hippocampal JNK (SoukhakLari et al., 2018c). Therefore, in the present study, it was assessed to see if the attenuating effect of nanocurcumin on chemical seizure was associated with JNK deactivation. However, the results of Western blot analysis revealed that curcumin could not reduce PTZ induced hippocampal JNK activation. Therefore, it seems that JNK modulation is not involved in the attenuating effect of a single treatment of curcumin on PTZ induced seizure. If JNK deactivation does not play a role in the anti-seizure effect of curcumin nanoparticle, what other mechanisms might be involved? Curcumin was suggested to act as an effective anti-inflammatory and antioxidant molecule (Dhir, 2018). The oxidative stress and neuroinflammation are known as the two major pathological events in seizure and epilepsy (Kobylarek et al., 2019). Hence, the anti-oxidative and anti-inflammatory properties of curcumin nanoparticle might serve as the potential mechanisms of the antiseizure effect of this molecule.

\section{Conclusion}

In brief, the results of the current study indicated that a single oral dose of BSA-based nanocurcumin, attenuates the severity of seizure both in i.v.PTZ and i.p.PTZ paradigms of status epilepticus in the mice. Additionally, it was shown that PTZ over activates hippocampal JNK signaling and the antiepileptic effect of nanocurcumin is not associated with the modulation of PTZ induced JNK over activation.

\section{Acknowledgments}

This work was supported by a grant (No. 98-01-5719866) from Shiraz University of Medical Sciences, Shiraz, Iran. The authors wish to thank Mr. H. Argasi 
at the Research Consultation Center (RCC) of Shiraz University of Medical Sciences for his invaluable assistance in editing this manuscript.

\section{Conflict of interest}

The authors declare that they have no conflict of interests.

\section{References}

Aggarwal BB, Sundaram C, Malani N, Ichikawa H. Curcumin: the Indian solid gold. In: The molecular targets and therapeutic uses of curcumin in health and disease. Boston: Springer, 2007, p.1-75. https://doi.org/10.1007/978-0-387-46401-5_1

Agarwal NB, Jain S, Nagpal D, Agarwal NK, Mediratta PK, Sharma KK. Liposomal formulation of curcumin attenuates seizures in different experimental models of epilepsy in mice. Fund Clin Pharmacol 2013; 27: 169-72. https:// doi.org/10.1111/j.1472-8206.2011.01002.x

Akula KK, Kulkarni SK. Effect of curcumin against pentylenetetrazol-induced seizure threshold in mice: Possible involvement of adenosine A1 receptors. Phytother Res 2014; 28: 714-21. https://doi.org/10.1002/ptr.5048

Amiri E, Ghasemi R, Moosavi M. Agmatine protects against 6-ohda-induced apoptosis, and erk and akt/gsk disruption in sh-sy5y cells. Cell Mol Neurobiol 2016; 36: 829-838. https://doi.org/10.1007/s10571-015-0266-7

Ben J, de Oliveira PA, Gonçalves FM, Peres TV, Matheus FC, Hoeller AA, et al. Effects of pentylenetetrazole kindling on mitogen-activated protein kinases levels in neocortex and hippocampus of mice. Neurochem Res 2014; 39: 2492500. https://doi.org/10.1007/s11064-014-1453-5

Buckmaster PS, Wen X, Toyoda I, Gulland FM, Van Bonn W. Hippocampal neuropathology of domoic acid-induced epilepsy in california sea lions (zalophus californianus). J Comp Neurol 2014; 522: 1691-706. https://doi. org/10.1002/cne.23509

Choudhary KM, Mishra A, Poroikov VV, Goel RK. Ameliorative effect of curcumin on seizure severity, depression like behavior, learning and memory deficit in post-pentylenetetrazole-kindled mice. Eur J Pharmacol 2013; 704: 33-40. https://doi.org/10.1016/j.ejphar.2013.02.012

Cole-Edwards KK, Musto AE, Bazan NG. c-Jun N-terminal kinase activation responses induced by hippocampal kindling are mediated by reactive astrocytes. J Neurosci 2006; 26: 8295-304. https://doi.org/10.1523/JNEUROSCI.1986-05.2006
Collett GP, Campbell FC. Curcumin induces c-jun n-terminal kinase-dependent apoptosis in het116 human colon cancer cells. Carcinogenesis 2004; 25: 2183-9. https://doi. org/10.1093/carcin/bgh233

Delfiya DA, Thangavel K,AmirthamD. Preparation of curcumin loaded egg albumin nanoparticles using acetone and optimization of desolvation process. Protein J 2016; 35: 124-35. https://doi.org/10.1007/s10930-016-9652-3

Dhir A. Curcumin in epilepsy disorders. Phytother Res 2018; 32: 1865-75. https://doi.org/10.1002/ptr.6125

Drion CM, Borm LE, Kooijman L, Aronica E, Wadman WJ, Hartog AF, et al. Effects of rapamycin and curcumin treatment on the development of epilepsy after electrically induced status epilepticus in rats. Epilepsia 2016; 57: 68897. https://doi.org/10.1111/epi.13345

Duncan JS, Sander JW, Sisodiya SM, Walker MC. Adult epilepsy. Lancet 2006; 367: 1087-100. https://doi.org/10.1016/S0140-6736(06)68477-8

Flora G, Gupta D, Tiwari A. Nanocurcumin: a promising therapeutic advancement over native curcumin. Crit Rev Ther Drug Carrier Syst 2013;30:331-68.https://doi.org/10.1615/ CritRevTherDrugCarrierSyst.2013007236

Geng S, Wang S, Zhu W, Xie C, Li X, Wu J, et al. Curcumin suppresses JNK pathway to attenuateBPA-induced insulin resistanceinLO2 cells. BiomedPharmacother2018;97:1538-43. https://doi.org/10.1016/j.biopha.2017.11.069

Goel A, Kunnumakkara AB, Aggarwal BB. Curcumin as "curecumin": from kitchen to clinic. Biochem Pharmacol 2008; 75: 787-809. https://doi.org/10.1016/j. bcp.2007.08.016

Hashemian M, Anissian D, Ghasemi-Kasman M, Akbari A, Khalili-Fomeshi M, Ghasemi S, et al. Curcumin-loaded chitosan-alginate-STPP nanoparticles ameliorate memory deficits and reduce glial activation in pentylenetetrazol-induced kindling model of epilepsy. Prog Neuropsychopharmacol Biol Psychiatry 2017; 79: 462-71. https://doi. org/10.1016/j.pnpbp.2017.07.025

Hsieh CL, Lin JJ, Chiang SY, Su SY, Tang NY, Lin GG, et al. Gastrodia elata modulated activator protein 1 via c-Jun $\mathrm{N}$-terminal kinase signaling pathway in kainic acid-induced epilepsy in rats. J Ethnopharmacol 2007; 109: 2417. https://doi.org/10.1016/j.jep.2006.07.024

Huang RQ, Bell-Horner CL, Dibas MI, Covey DF, Drewe JA, Dillon GH. Pentylenetetrazole-induced inhibition of recombinant gamma-aminobutyric acid type A (GABA(A)) receptors: mechanism and site of action. J Pharmacol Exp Ther 2001; 298: 986-95. 
Inaloo S, Pirsalami F, Dastgheib M, Moezi L. The effects of dairy products on seizure tendency in mice. Heliyon 2019; 5: e01331. https://doi.org/10.1016/j.heliyon.2019. e01331

Jahan AA, Rad A, Ghanbarabadi M, Amin B, Mohammad-Zadeh $\mathrm{M}$. The role of serotonin and its receptors on the anticonvulsant effect of curcumin in pentylenetetrazol-induced seizures. Life Sci 2018; 211: 252-60. https:// doi.org/10.1016/j.1fs.2018.09.007

Jithan AV, Madhavi K, Madhavi M, Prabhakar K. Preparation and characterization of albumin nanoparticles encapsulating curcumin intended for the treatment of breast cancer. Int J Pharm Invest 2011; 1: 119-25. https://doi. org/10.4103/2230-973X.82432

Karimi M, Bahrami S, Ravari SB, Zangabad PS, Mirshekari H, Bozorgomid $\mathrm{M}$, et al. Albumin nanostructures as advanced drug delivery systems. Expert Opin Drug Del 2016; 13: 1609-23. https://doi.org/10.1080/17425247.2016.1193149

Kaur H, Bal A, Sandhir R. Curcumin supplementation improves mitochondrial and behavioral deficits in experimental model of chronic epilepsy. Pharmacol Biochem Behav 2014; 125: 55-64. https://doi.org/10.1016/j.pbb.2014.08.001

Khadrawy YA, Sawie HG, Hosny EN. Neuroprotective effect of curcuminnanoparticlesagainstratmodelofstatusepilepticus induced by pilocarpine. J Complement Integr Med 2018; 15. https://doi.org/10.1515/jcim-2017-0117

Khan MS, Muhammad T. Dietary supplementation of the antioxidant curcumin halts systemic LPS-induced neuroinflammation-associated neurodegeneration and memory/synaptic impairment via the JNK/NF- $\mathrm{KB} / \mathrm{Akt}$ signaling pathway in adult rats. Oxid Med Cell Longev 2019; 2019: 7860650. https://doi.org/10.1155/2019/7860650

Kiasalari Z, Roghani M, Khalili M, Rahmati B, Baluchnejadmojarad T. Antiepileptogenic effect of curcumin on kainate-induced model of temporal lobe epilepsy. Pharm Biol 2013; 51: 1572-8. https://doi.org/10.3109/13880209.2013.803128

Kim TH, Jiang HH, Youn YS, Park CW, Tak KK, Lee S, et al. Preparation and characterization of water-soluble albumin-bound curcumin nanoparticles with improved antitumor activity. Int J Pharm 2011; 403: 285-91. https://doi. org/10.1016/j.ijpharm.2010.10.041

Kobylarek D, Iwanowski P, Lewandowska Z, Limphaibool N, Szafranek S, Labrzycka A, et al. Advances in the potential biomarkers of epilepsy. Front Neurol 2019; 10. https://doi. org/10.3389/fneur.2019.00685

Kocaadam B, Sanlier N. Curcumin, an active component of turmeric (curcuma longa), and its effects on health. Crit Rev Food Sci Nutr 2017; 57: 2889-95. https://doi.org/10.1 080/10408398.2015.1077195

Kratz F. Albumin as a drug carrier: Design of prodrugs, drug conjugates and nanoparticles. J Control Release 2008; 132: 171-83. https://doi.org/10.1016/j.jconrel.2008.05.010

Kumar V, Prakash C, Singh R, Sharma D. Curcumin's antiepileptic effect, and alterations in nav1.1 and nav1.6 expression in iron-induced epilepsy. Epilepsy Res 2019; 150: 7-16. https://doi.org/10.1016/j.eplepsyres.2018.12.007

Kupferberg H. Animal models used in the screening of antiepileptic drugs. Epilepsia 2001; 42 Suppl 4: 7-12. https:// doi.org/10.1046/j.1528-1157.2001.0420s4007.x

Loscher W, Honack D, Fassbender CP, Nolting B. The role of technical, biological and pharmacological factors in the laboratory evaluation of anticonvulsant drugs. III. Pentylenetetrazole seizure models. Epilepsy Res 1991; 8: 17189. https://doi.org/10.1016/0920-1211(91)90062-K

Loscher W, Lehmann H. L-deprenyl (selegiline) exerts anticonvulsant effects against different seizure types in mice. J Pharmacol Exp Ther 1996; 277: 1410-7.

Lowry OH, Rosebrough NJ, Farr AL, Randall RJ. Protein measurement with the folin phenol reagent. J Biol Chem 1951; 193: 265-75.

Mandhane SN, Aavula K, Rajamannar T. Timed pentylenetetrazol infusion test: a comparative analysis with s.C.PTZ and MES models of anticonvulsant screening in mice. Seizure 2007; 16: 636-44. https://doi.org/10.1016/j.seizure.2007.05.005

Mielke K, Brecht S, Dorst A, Herdegen T. Activity and expression of JNK1, p38 and ERK kinases, c-Jun N-terminal phosphorylation, and c-jun promoter binding in the adult rat brain following kainate-induced seizures. Neuroscience 1999; 91: 471-83. https://doi.org/10.1016/S03064522(98)00667-8

Moezi L, Yahosseini S, Jamshidzadeh A, Dastgheib M, Pirsalami F. Sub-chronic boldine treatment exerts anticonvulsant effects in mice. Neurol Res 2018; 40: 146-52. https:// doi.org/10.1080/01616412.2017.1402500

Moosavi M, Abbasi L, Zarifkar A, Rastegar K. The role of nitric oxide in spatial memory stages, hippocampal erk and camkii phosphorylation. Pharmacol Biochem Behav 2014; 122: 164-72. https://doi.org/10.1016/j.pbb.2014.03.021

Morgan L, Neame SJ, Child H, Chung R, Shah B, Barden L, 
et al. Development of a pentylenetetrazole-induced seizure model to evaluate kinase inhibitor efficacy in the central nervous system. Neurosci Lett 2006; 395: 143-8. https:// doi.org/10.1016/j.neulet.2005.10.068

Nutt DJ, Taylor SC, Little HJ. Optimizing the pentetrazol infusion test for seizure threshold measurement. J Pharm Pharmacol 1986; 38: 697-8. https://doi. org/10.1111/j.2042-7158.1986.tb03114.x

Peng DU, Tang HY, Xin LI, Lin HJ, Peng WF, Yu MA, et al. Anticonvulsive and antioxidant effects of curcumin on pilocarpine-induced seizures in rats. Chin Med J (Engl) 2012; 125: 1975-9.

Rein MJ, Renouf M, Cruz-Hernandez C, Actis-Goretta L, Thakkar SK, da Silva Pinto M. Bioavailability of bioactive food compounds: A challenging journey to bioefficacy. Br J Clin Pharmacol 2013; 75: 588-602. https://doi.org/10.1111/j.1365-2125.2012.04425.x

Rogawski MA. Molecular targets versus models for new antiepileptic drug discovery. Epilepsy Res 2006; 68: 22-8. https://doi.org/10.1016/j.eplepsyres.2005.09.012

Saha L, Chakrabarti A, Kumari S, Bhatia A, Banerjee D. Antiapoptotic and neuroprotective role of Curcumin in Pentylenetetrazole (PTZ) induced kindling model in rat. Indian J Exp Biol 2016; 54: 133-41.

Scheepens A, Tan K, Paxton JW. Improving the oral bioavailability of beneficial polyphenols through designed synergies. Genes Nutr 2010; 5: 75-87. https://doi.org/10.1007/ s12263-009-0148-Z

Shafaroodi H, Moezi L, Ghorbani H, Zaeri M, Hassanpour $\mathrm{S}$, Hassanipour M, et al. Sub-chronic treatment with pioglitazone exerts anti-convulsant effects in pentylenetetrazole-induced seizures of mice: the role of nitric oxide. Brain Res Bull 2012; 87: 544-50. https://doi.org/10.1016/j. brainresbull.2012.02.001

Shafaroodi H, Oveisi S, Hosseini M, Niknahad H, Moezi L. The effect of acute aripiprazole treatment on chemically and electrically induced seizures in mice: the role of nitric oxide. Epilepsy Behav 2015; 48: 35-40. https://doi. org/10.1016/j.yebeh.2015.05.018

Sookhaklari R, Geramizadeh B, Abkar M, Moosavi M. The neuroprotective effect of BSA-based nanocurcumin against 6-OHDA-induced cell death in SH-SY5Y cells. Basic Clin Neurosci 2019; 9: 92-100.

SoukhakLari R, Moezi L. Curcumin-loaded bsa nanoparticles protect more efficiently than natural curcumin against scopolamine-induced memory retrieval deficit. Basic Clin Neurosci 2019; 10: 157-64.
SoukhakLari R, Moezi L, Pirsalami F, Ashjazadeh N, Moosavi M. Curcumin ameliorates scopolamine-induced mice memory retrieval deficit and restores hippocampal p-Akt and p-GSK-3 3 . Eur J Pharmacol 2018a; 841: 28-32. https:// doi.org/10.1016/j.ejphar.2018.10.012

SoukhakLari R, Moezi L, Pirsalami F, Ashjazadeh N, Moosavi M. The passive avoidance memory improving effect of curcumin in young adult mice: considering hippocampal MMP-2, MMP-9 and Akt/GSK3 $\beta$. PharmaNutrition 2018b; 6: 95-9. https://doi.org/10.1016/j.phanu.2018.05.002

SoukhakLari R, Moezi L, Pirsalami F, Moosavi M. The effect of BSA-based curcumin nanoparticles on memory and hippocampal MMP-2, MMP-9, and MAPKs in adult mice. J Mol Neurosci 2018c; 65: 319-26. https://doi.org/10.1007/s12031-018-1104-4

Spigolon G, Veronesi C, Bonny C, Vercelli A. c-Jun N-terminal kinase signaling pathway in excitotoxic cell death following kainic acid-induced status epilepticus. Eur J Neurosci 2010; 31: 1261-72. https://doi.org/10.1111/j.1460-9568.2010.07158.x

Sumanont Y, Murakami Y, Tohda M, Vajragupta O, Watanabe $\mathrm{H}$, Matsumoto K. Effects of manganese complexes of curcumin and diacetylcurcumin on kainic acid-induced neurotoxic responses in the rat hippocampus. Biol Pharm Bull 2007; 30: 1732-9. https://doi.org/10.1248/ bpb.30.1732

Tai TY, Warner LN, Jones TD, Jung S, Concepcion FA, Skyrud DW, et al. Antiepileptic action of c-jun n-terminal kinase (jnk) inhibition in an animal model of temporal lobe epilepsy. Neuroscience 2017; 349: 35-47. https://doi. org/10.1016/j.neuroscience.2017.02.024

Tang F, Hartz AMS, Bauer B. Drug-resistant epilepsy: multiple hypotheses, few answers. Front Neurol 2017; 8: 301. https://doi.org/10.3389/fneur.2017.00301

Tønnesen HH. Solubility, chemical and photochemical stability of curcumin in surfactant solutions. Studies of curcumin and curcuminoids, XXVIII. Die Pharmazie 2002; 57: 820-4.

Vidaurre J, Gedela S, Yarosz S. Antiepileptic drugs and liver disease. Pediatr Neurol 2017; 77: 23-36. https://doi. org/10.1016/j.pediatrneurol.2017.09.013

Wahlstrom B, Blennow G. A study on the fate of curcumin in the rat. Acta Pharmacol Toxicol (Copenh) 1978; 43: 86-92. https://doi.org/10.1111/j.1600-0773.1978.tb02240.x

Wang Z, Chen Y, Lü Y, Chen X, Cheng L, Mi X, et al. Effects of JIP3 on epileptic seizures: evidence from temporal 
lobe epilepsy patients, kainic-induced acute seizures and pentylenetetrazole-induced kindled seizures. Neuroscience 2015; 300: 314-24. https://doi.org/10.1016/j.neuroscience. 2015.05 .008

Yang DD, Kuan CY, Whitmarsh AJ, Rinócn M, Zheng TS, Davis RJ, et al. Absence of excitotoxicity-induced apoptosis in the hippocampus of mice lacking the jnk3 gene. Nature 1997; 389: 865-70. https://doi.org/10.1038/39899

Yarza R, Vela S, Solas M, Ramirez MJ. c-Jun N-terminal kinase (JNK) signaling as a therapeutic target for Alzheimer's disease. Front Pharmacol 2016; 6: 321. https://doi. org/10.3389/fphar.2015.00321

Zhang W, Wang X, Yu M, Li JA, Meng H. The c-Jun N-termi- nal kinase signaling pathway in epilepsy: activation, regulation, and therapeutics. J Recept Signal Transduct 2018; 38: 492-8. https://doi.org/10.1080/10799893.2019.15904 10

Zhao W, Zhou X, Qi G, Guo Y. Curcumin suppressed the prostate cancer by inhibiting jnk pathways via epigenetic regulation. J Biochem Mol Toxicol 2018; 32: e22049. https://doi.org/10.1002/jbt.22049

Zhao Y, Spigolon G, Bonny C, Culman J, Vercelli A, Herdegen T. The jnk inhibitor d-jnki-1 blocks apoptotic jnk signaling in brain mitochondria. Mol Cell Neurosci 2012; 49: 30010. https://doi.org/10.1016/j.mcn.2011.12.005 